PR OST, Antoine. Historia da vida privada. São Paulo:

Companhia das Letras, 1992. (Fronteiras do espaço privado)

SANTOS, Milton. Novos rumos da geografia brasileira. São Paulo: HUCITEC, 1982.

O meio técnico-cientffico e a urbanizaçáo no

Brasil. São Paulo: Espaço e Debates, n. 25, 1988a.
HUCITEC, $1988 \mathrm{~b}$.

Metamorfose do espaço habitado. São Paulo:

VIRILLIO, Paul. Guerra pura. São Paulo: Brasiliense, 1983.

\title{
DEPENDÊNCIA E DESENVOLVIMENTO NA AMÉRICA LATINA: O PAPEL DOS ESTADOS NACIONAIS NA NOVA ORDEM MUNDIAL
}

\author{
RONALDO BALTAR ${ }^{1}$
}

BALTAR, $R$. Dependência e Desenvolvimento na América Latina: o papel dos Estados nacionais na nova ordem mundial. Semiraz: Ci. Soc./Hum ${ }_{s y}$ Londrina, vo 15, no 3, p. 245-249, set. 1994.

RESUAO: A questáo básica proposta neste texto visa discutir a relação entre Estado e economia da perspectiva da internacio nalização dos mercados e do capital, parindo da premissa de que a compreensão do desenvolvimento do capitalismo moderno estå além dos estudos que possuem como objeio os Estados nacionais isoladamente. As questöes referentes a compreensão das transformaçes pollticas na América Latina passam a requerer analises integradas, de forma a que seja possivel dimensionar o papel das crises econômicas a das mudanças de regimes polticos na especificidade do processo de desenvolvimento car pitalista dos palses latinomamericanos.

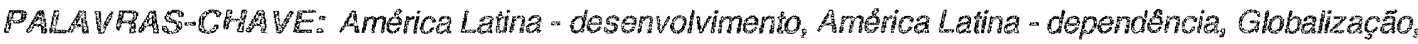 Mercado - internacionalizaço}

\section{I- TNTRODUCRO}

A questão básica proposta neste texto visa uma dis. cussão, ainda inicial sobre a relaçăo entre Estado e eco. nomia na América Latina da perspectiva da internaciona. lização dos mercados e do capital, partindo da premissa de que a compreensão do desenvolvimento do capitalis. mo moderno está além dos estudos que possuem como objeto os Estados nacionais isoladamente. As questões referentes à compreensão das transformaçốes politicas na América Latina, sobretudo, passam a requerer anălim ses integradas, de forma que seja possivel dimensionar o papel das crises económicas e das mudanças de regimes políticos na especificidade do processo de desenvolvi. mento capitalista dos paises latino-americanos.

O centro deste tipo de abordagem está na análise dos liames entre ordem política democrática, autoritarismo e crise económica. Difere, no entanto, dos estudos que procuraram responder a esta questäo a partir de instrumentos analiticos estritamente institucionais, tais como análises eleitorais, estudos sobre o discurso e o com. portamento de grupos politicos a a comparação entre tipos de instituiçóes polticas de palses diferentes em situa çóes paralelas (democratização, etc. . Também difere da análise marxista ortodoxa, na medida em que esta rende a subdimensionar o papel da esfera politica na conformaçăo do processo de desenvolvimento econômico, atribuindo uma relação de reciprocidade mecânica entre in teresses politicos e interesses econômicos, ambos englobados ao conceito de interesses de classe. Diverge tambẻm da análise econômica pura, ume vez que o instrumental analitico da economia prende-se fundamentalmente na reflexão dedutiva por comparaçăo de modelos. Diante da atual diversidade de caminhos apresentados pelo processo de expansão do capitalismo mundial, os modelos tradicionais de interpretação da dinâmica capitalista, amparados em paradigmas históricos como a revolução industrial inglesa, por exemplo, não conseguem reunir elementos suficientes para a compreensão das atuais transformaçőes vividas pelas sociedades ocidenm tais.

O caminho para tornar esta reflexão possivel segue

1 - Departamento de Ciências Sociais da Universidade Estadual de Londrina, Caixa Postal 600i, Londrina, Paraná, Brasif, CEP 86051-970. 
os estudos que procuram estabelecer as formas às quais a relação entre Estado e economia tenha assumido para formar um novo padrão de desenvolvimento capitalista. Os conceitos-chave para esta operação metodológica são Estado e mercado, ambos vistos sob a perspectiva histórica, e observados cada qual sob sua lógica própria de funcionamento. Isto implica abordar a relação Estado e economia (poder público e interesses privados) do ponto de vista de um sistema de relaçöes interativas, diferentemente de um modelo onde prevalece a subordinaçäo de uma esfera a outra.

\section{2 - ESTADO, MERCADO E CAPITAL NO CON- TEXTO DAS RELAÇŌES INTERNACIONAIS}

A localização histórica dos conceitos de Estado e mercado deve vir acompanhada do redimensionamento dos niveis de integração internacional ao qual estão submetidos a cada momento. Neste sentido, para uma proposta de análise integrada, o conjunto de rela" ções internacionais deve passar a ser considerado, ao lado das variáveis Estado e mercado, como sendo também uma variảvel-chave para a compreensão da dinâmica do desenvolvimento atual.

A inserção das relações internacionais como objeto de estudo suscita três tipos de entendimentos sobre as tensões existentes entre os organismos representativos dos interesses nacionais (GERCHENKRON, 1970):

1 . posição do conflito, sugere que as relaçōes antre inte" resses nacionais e internacionais fundamentam-se em confrontos constantes, aos quais só sobrepõe-se algum tipo de ordem a partir da força de subordinação que determinados Estados exercem sobre outros;

2. posição liberal, parte da premissa de que as relações entre nações valem-se de um sistema equilibrado de cooperação mủtua $a_{\tilde{a}}$ fundamentado na troca de mercadorias e regulado pelo mercado internacional;

3. posição da hegemonia internacional, a qual presume um grau concomitante de conflito e de cooperaçäo em um sistema que, embora conduzido por interesses de determinadas naçôes (hegemônicas), abremse também à realização de interesses soberanos não hegemônicos através de alianças, parcerias, acordos e outros insurumentos de normatização dos interesses geopoliticos e económicos de cada nação ou de grupos de nações.

A primeira anålise das relações econômicas internacionais tende a subestimar a capacidade dos Estados nacionais em decidirem com qualquer grau de autonomia suas questões de política externa, o que implica admitir. por conseqüência, a incapacidade de uma condição so. berana dos rumos da política interna.

A segunda conduz a uma distorção sobre a dinâmica do sistema. Ao ignorar as tensões do sistema econô. mico internacional e das relações politicas entre os Esta. dos, considerando o conflito como exceçäo em um modelo tipicamente caracterizado pelo equilibrio, esta proposição dificulta o entendimento sobre as transformaçōes Semina Ci. Soc./Hum., v. 15, n. 3, p. 245-249 ocorridas na esfera económica interne de ceda pals.

A análise da hegemonia entre os Estados permite o estudo das interaçőes entre o plano polftico e econômico de uma forma mais clara do que as outras duas visões; procurando-se evitar o risco de subdimensionar as determinações locais de politica económica ou de superestimar a capacidade de absorçăo das diverghnchas regionais pelo mercado internacional. Neste sentido, os liames da política e da economia entre as naçóes devem ser desvendados através do enfoque sobre as interaçes politi cas originárias concomitantemente de pressöes internase externas.

Enquanto esferas distintas, polfica e economia seguem dinâmicas próprias de funcionamento, de tal forma que as pressöes ao nivel politico podem ou não repercutir de forma diferenciada ao nivei econômico. $\mathrm{O}$ elemento central para a anålise integrada corresponde, portanto, ao enfoque dos aspectos politicos das açōes econômicas. da resultante deste conjunto de medidas que se forma a ordem hegemónica do sistema, e por sua vez, \& das at. ternativas e repercussões regionais destas açőes que so alimenta o conflito e as tensőes no sistema.

Desta forma duas questões passam a orientar as reflexões sobre a relação Estado/economia dentro do contexto da nova ordem mundial: os espaços de definição da soberania interna e externa do Estado, e a globali. zaçăo dos mercados. Aqui, ocorre um desiocamento em lelação a tradição de estudos neste campo no âmbito das ciências sociais (aproximando-se da análise econónica). uma vez em que o foco de análise passa a ser desviado do capital para o mercado. Este tipo de deslocamento in objeto de estudos possui um significado metodolbgico importante: trata se da busca de uma abordagem inte: disciplinar sobre um problema tradicionalmente estuda. do sob enfoques diferentes dentro de cada disciplina jes ciências sociais, em especial a socioiogia a a ciência point sa.

Em uma anålise econömice tradicional, por exemo do. o papel do Estado ne economia só recebe atençä quando ysto sob aspectr da alccacab a de redistibut ̧ăo de recursos. 0 que interessa neste tipo de estudo mensurar, através de diversos tipos de indicadores, on. vel de acumulação de capital, procurando identificar os elementos que aceleram ou retardam o itmo de crescimento da taxa de luxo (ou do crescimento econbmico). Neste sentido, o capital ganha uma dimeneão aurônoma nas relaçôes sociais, o que reduz os grupos sociais ab conceito de agentes econômícos, isto है. a sujeitos serr organizaçảo, interesses, racionalidade ou ideologias par. ticulares, gerando a pressuposição de que estes agentes possuem um comportamento previsivel, na medida em que guiam-se täo somente pelas "regras do mercado" ou pela "lei da oferta e da demanda".

Por Dutro lado, estudos sociológicos têm tido a tendência a prenderem-se na açăo particular dos sujeitos sociais, concentrando-se apenas na tipificação do comportamento polftico destes grupos perante situações historicas especificas, normalmente tendo como objeto imediato a análise dos discursos de lideranças polfiticas 
ou, de associações de classe. Por sua vez, o enfoque dado através da ciência política a este tipo de problema têm sido, em grande parte, restrito a estudos comparativos, os quais redundam em descrições de formas institucionais frente a momentos históricos determinados, como a ascensão do autoritarismo ou as transições para a democracia.

Diante dos limites impostos à investigação isolada dentro de cada disciplina, muitos sociólogos, politólogos e economistas vêm postulando a análise integrada como fórmula mais eficaz para possibilitar a compreensão das transformações ocorridas no padrão de desenvolvimento capitalista a partir da década de 80 . Dentro desta perspectiva, o deslocamento da noção de internacionalização do capital para a globalização do mercado, como elemento chave para compreensão das mudanças no sistema, não significa uma negação da referência a uma estrutura de classes, tal como é entendido o conceito de capital na tradição das ciências sociais. Centralizar a reflexão no processo de globalização do mercado significa reconhecer que o capital, por ser uma forma específica de propriedade numa dada estrutura social, possui, em alguma medida, uma dimensão nacional, o que the impõe um limite na perspectiva de globalização. Já o mercado, por ser visto como espaço onde se manifestam relações sociais próprias do processo de acumulação, serve como instrumento analítico mais adequado para uma compreensão da dinâmica de globalização e seus efeitos sobre a articulação entre Estado e economia.

Globalização do mercado significa pressupor que há um processo gradativo no qual os mercados locais tornam-se cada vez mais abertos a capitais que, embora circulando internacionalmente, possuem um vinculo nacional de origem (por serem propriedade de algue̊m) ${ }_{n} \mathrm{Na}$ medida em que a globalização assume uma proporção generalizada entre as nações, diversos elementos que estruturam o sistema passam a estar em cheque, tais como os conceitos de soberania, nacionalidade, desenvol. vimento, dependência, entre outros. Esta operação teórica pretende tornar mais eficiente o estudo das tensões internas e externas que existem nos arranjos conseqüentes deste processo e que, por conseguinte, funda. mentam o padrão de desenvolvimento capitalista atual. Padrão este que passa a ser caracterizado agora não mais pela internacionalização do capital, mas fundamentalmente pela globalização dos mercados.

Os conceitos de internacionalização e globalização diferem-se basicamente pelo sentido de manutenção ou perda das referências nacionais. Assim, a internacionalização significa um processo político, econômico ou cultural onde hă interação entre países diferentes sem que haja, no entanto, perda das suas referências nacionais. Já o conceito de globalização procura identificar aquelas in. terações políticas econômicas ou culturais onde existe urna forma de integração (unificação), que tem como conseqüência a perda das referências nacionais. Em outras palavras, a internacionalização requer a existência de fronteiras nacionais, enquanto a globalização significa a superação destas fronteiras na formação de unidades Semina Ci. Soc $/$ Hum $_{\circ}$ v。 15, no 3, p. 245-249 globais. É neste sentido que o capital deve ser visto sob a perspectiva da internacionalização (pois enquanto propriedade não perde suas referências nacionais), enquanto o mercado pode ser analisado sob a ótica da globalização.

As tensōes locais e internacionais a que estäo submetidos os Estados, as quais exigem respostas politicas adequadas perante a globalização dos mercados, abrem possibilidades de arranjos sociais e programas de desenvolvimento que não se explicam por mecanismos de auto-regulação econômica. Neste sentido, em oposição à proposição neoliberal, o equilíbrio gerado por um comércio livre não é garantia nem fundamento de uma ordem internacional eqüânime, nem tampouco a garantia de existência de uma ordem nacional democrática.

\section{3 - O PAPEL DO ESTADO NO DESENVOLVIMENTO LATINO-AMERICANO}

Ao se localizar a discussão sobre a realidade atual da América Latina, a questão focalizada passa a tratar do grau possivel de liberdade (autonomia) que os Estados nacionais possuem sobre o "consenso de Washington", ou seja, procura-se avaliar quais as possibilidades de conjugação entre desenvolvimento, autonomia e democracia nos países do terceiro mundo.

O conceito de dependência readquire um papel de destaque para este tipo de reflexão, na medida em que pretende uma sintese entre diversas concepções sobre o desenvolvimento capitalista nas regiões periféricas do sistema, ao mesmo tempo em que propõe uma perspectiva integrada de análise entre a economia e a política.

$O$ debate conceitual que sustentava as diferentes compreensões sobre o desenvolvimento (e subdesenvolvimento), desde os anos 50, retratava uma polarização entre as proposições liberais e aquelas (socialistas e não socialistas) que preconizavam a inevitabilidade de uma intervenção estatal no processo de industrialização tardia. Este debate esteve presente nas formulações cepalinas, desempenhando um papel importante na definição da teoria do subdesenvolvimento assumida pelos seus mais expressivos representantes (Raúl Prebisch e Celso Furtado). A generalização da proposta da CEPAL, assumida na segunda metade da década de 50 como política desenvolvimentista em vários países latino-americaos (Brasil e México sobretudo), implicou em um esvaziamento das formulações liberais que preconizavam formas de industrialização sem a intervenção do Estado (BIELSHOWSKY, 1988).

O conjunto de argumentos que sustentavam a proposta cepalina estavam fundamentados no desequilibrio da balança de pagamentos entre a periferia e o centro do sistema. A deterioração dos termos de troca entre Europa e Estados Unidos de um lado, e o terceiro mundo de outro (excluia-se os paises do bloco socialista), constitula-se nesta perspectiva como o obståculo central ao desenvolvimento. Para superá-10, havia a necessidade do desencadeamento de um processo de industrialização, transformando as economias agro-exportadoras em econo- 
mias manufatureiras.

De posse deste diagnóstico, o problema transportava-se para os limites estruturais dos países latino-americanos. Estes limites dificultavam internamente a mudan. ça de economias de exportadores de matérias-primas para economias industrializadas segundo os prognósti. cos da CEPAL., os principais obstáculos estruturais (va: rianies em grau a intensidade em cada país latino-ame?" canol erans:

1) a hala de capital privado en abundancia para financiar a industrializaço;

2) a fala de um mercado inerne consumidor capaz do impulsionar e sustentar o desenvolvimento.

Aldotos astes problemas eravam a instabliobde

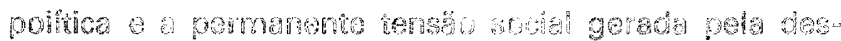

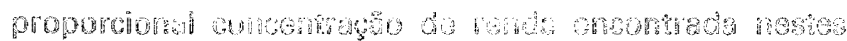

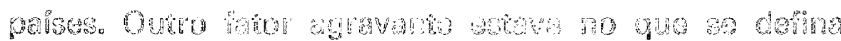

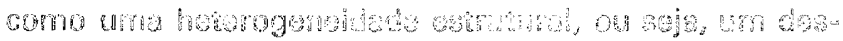

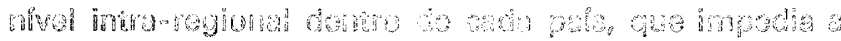

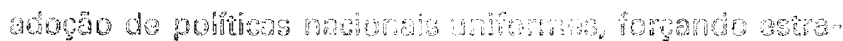

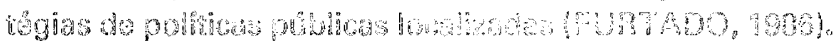

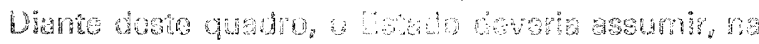

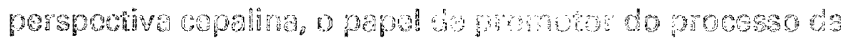

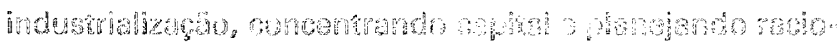

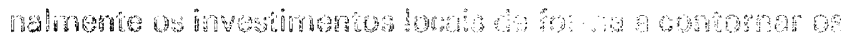

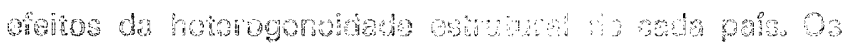

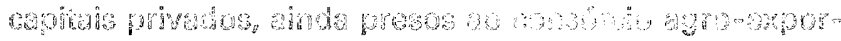

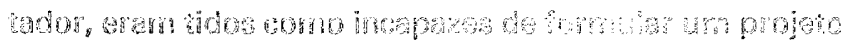

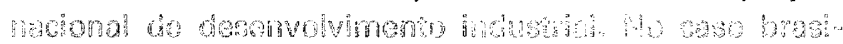

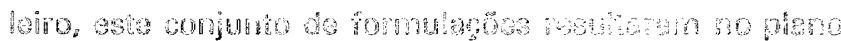

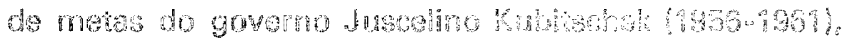

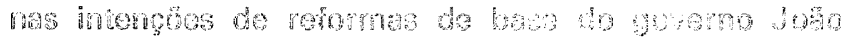

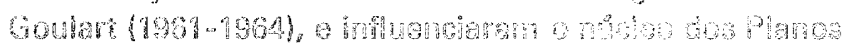

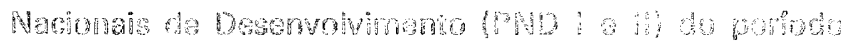
milditar (1904.4939)。

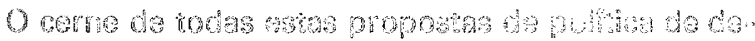

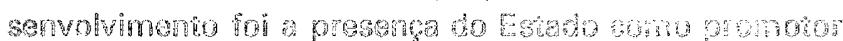

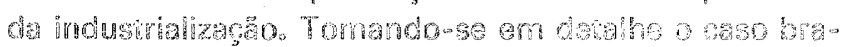

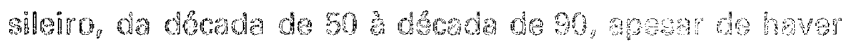
un vigoroso debate intelechal an tomo dos sonertos liborais, on oposich mia, gue ervoven persphagen como powan shmon.

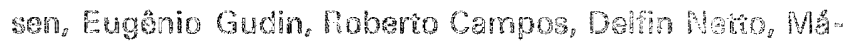
ro Henroge Smonsen, Femando Honem do Melo, Fasnendo Henrigug Cardoso, Cabs Furtado, Igrabur hangel.

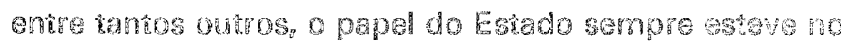

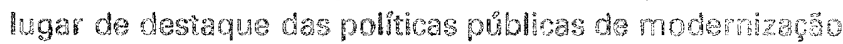

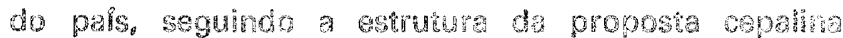
(BUELSHOWSKY.1988).

Embora honvesse a açu raciona do plenejanento pubico, orimendo a indusinalizaço. orocegso de den senvolvinemo não rewh tou em superaçoses do quadro de desequibrios hutra-regionals, nem no nivel de concenrraça de renda. Ao contrario, a 0 longo destes 40 anos de industrializaça orientada pelo Estado nacional, anda que desoboráveis em fases distintas, diversos indicadores que na decada de 50 caracterizavam o grau de subdesenSemina Ci. Soc Jurm., vo 15, n. 3, p. 245.249 volvimento, persistem ainda na década de 90 lanalfabetismo, pobreza absoluta crescente, malha viária precáric, altos indices de mortalidade infantil, êxodo rural, entrs

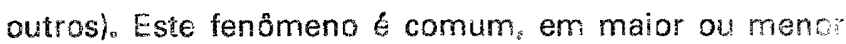
escala, a todos os palses latino-americanos que exper:mentaram algum tipo de projeto nacional de desenws. vimento.

Por outro lado, tambem o setor privado mosteg: se incapaz de articular um proieto privado de deramy. vimento nacionai, capaz de promover um pronese ds hu

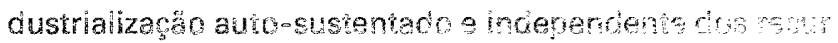

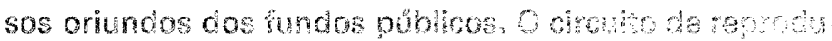

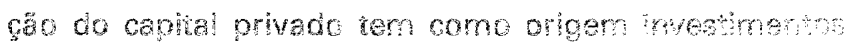

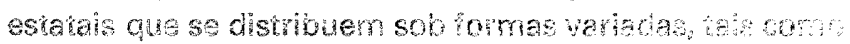

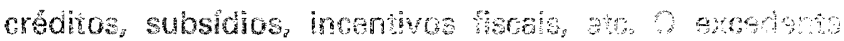

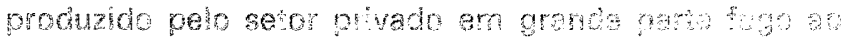

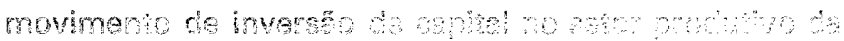

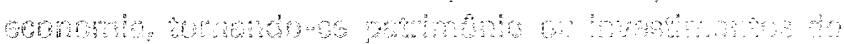

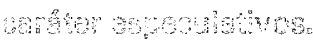

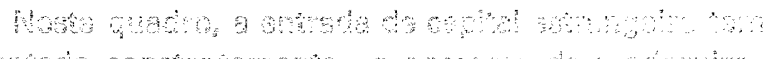

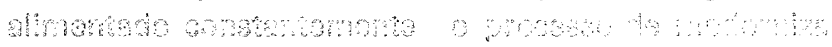

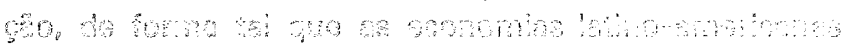

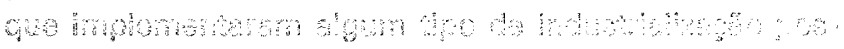

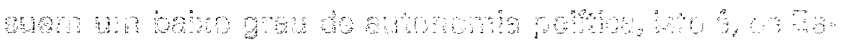

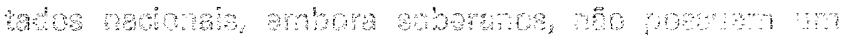

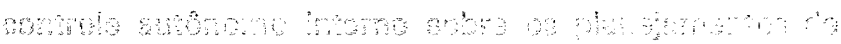

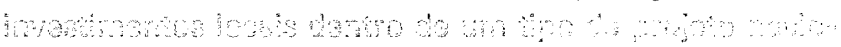

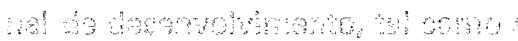

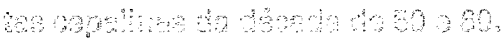

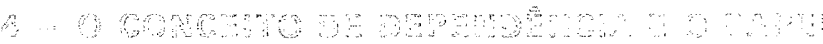

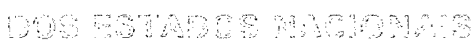

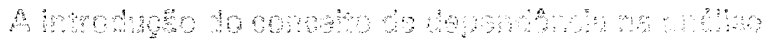

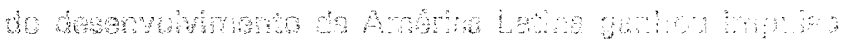

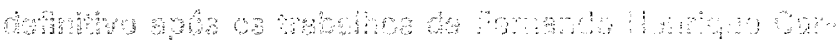

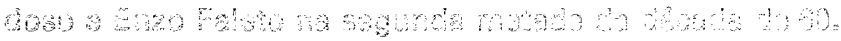

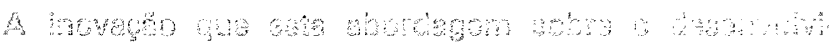

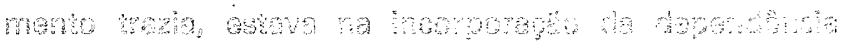

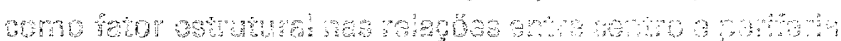

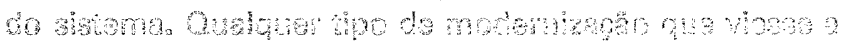

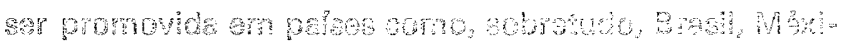

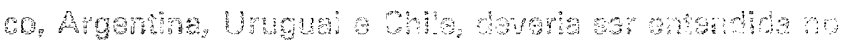

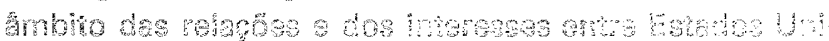

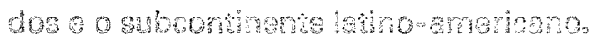

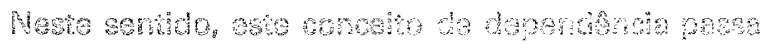

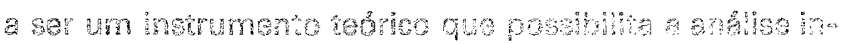

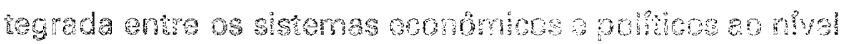

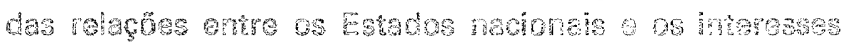
inemacionas. A pesthente dosta propose conorimel

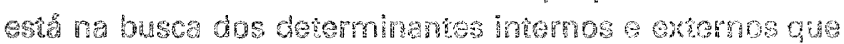

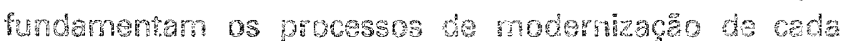
pels.

No entants, a dependencia recolocese hoje apos a crise do Estado dos anos $30 \odot 90$ dinerntemente do momento no qual fol formulada. Embora persista wigum desequilibrio nas relaços de troca entre os paises do centro e os de perteria, este parece näo ser mais un fa tor prinordial ma tipificaçă da depandencia ao longo dos
\end{abstract}


anos 80. As dividas externas, intermediadas e monitoradas por organismos internacionais como o Fundo Monetário Internacional (FMI), assumiram o papel determinante na forma de padronização das políticas de relações internacionais, sobretudo entre os Estados Unidos e Brasil, México, Argentina e Chile.

Soma-se a este novo padrão de dependência a crescente globalização dos mercados locais, fenômeno que foi acelerado a partir da segunda metade da década de 80 (início dos anos 90 no Brasil), seguindo os programas de ajuste do Fundo Monetário Internacional e do Banco Interamericano de Desenvolvimento.

A crise dos Estados nacionais, na década de 80 marca a concomitância de dois fenômenos: o esgotamento dos regimes militares ditatoriais e a incapacidade do poder público em manter-se como pólo promotor do processo de modernização econômica, em virtude das dívidas externas e internas contraídas ao longo dos anos 60 e 70 (SALLUM JUNIOR, 1988). Deste forma, O Estado perde a capacidade econômica de financiar o desenvolvimento ao mesmo tempo em que perde o suporte autoritário para dirigir as políticas públicas. Os perlodos de transiçäo passam a revelar um conjunto de demandas sociais organizadas, até então reprimidas, que não se contentam em passar ao largo da industrialização.

O projeto que emerge desta nova ordem política latino-americana, democratizada e parcialmente industrializada, encontra uma barreira na crise de financiamento do Estado. O impasse que se constrói atualmente e prolonga as transições, está ancorado, desta forma, nos seguintes elementos:

1) a conquista de espaços políticos de negociação dentro do Estado por setores sociais organizados que ${ }_{0}$ ao longo do período ditatorial, estiveram à margem dos investimentos públicos;

2) a incapacidade econômica do Estado, endividado, de ser o centro do projeto de desenvolvimento; e

3) a incapacidade política do Estado, sem autonomia perante novo quadro de interesses internacionais, em atender as demandas sociais que agora se fazem representar no cenário polf́tico nacional.

As tensões geradas por estes conflitos agravam-se, ao se projetar o caminho das transições a longo prazo, na medida em que, embora surjam projetos neoliberais de orientação externa como solução para a América Latina, em nenhum destes paises se identifica a construção de um projeto nacional de desenvolvimento fundamentado em capitais privados. Todas as soluções, sobretudo as neoliberais, ainda se baseiam no Estado como financiador de industrialização. A inversão dos programas de modernização (neoliberais) está no fato de que os investimentos públicos não devam mais ser canalizados para empresas de caráter estatal mas ir direttamente ao setor privado. Significa portanto, uma radicalização da atividade de apropriação privada dos fundos públicos, elemento constante na vida política dos paises latino-americanos, em especial no Brasil.

A questão que se deve buscar, para a compreensão da possibilidade de conjunção duradoura entre desenvolvimento, democracia e autonomia na América Latina reside, assim, em que tipos de arranjos sociais locais sustentam estes novos projetos de modernização, tendo-se como parâmetro a crise do Estado e a forma na qual se configura a dependência no quadro atual das relações politicas internacionais.

BALTAB, F. Dependence and Development in Latin America: the role of nacional States in global new order. Sempine:

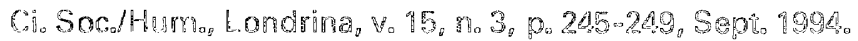

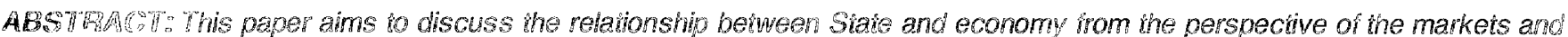
capizals' internationalization. The basic premise is that the comprehension of the modern capitalism developmen is beyond the studies that take into account the national States isolately. The question regarding the comprehension of these political transiormations in Latin America needs integrated analysis to become possible the understanding of the real dimension of the role that economics and political crisis play in specific capitalist development process of Latin-American couniries.

KEY-WORDS: Latin America - development, Latin America - dependence, Globalization, Markế - internationalization

\section{REFERÊNCIAS BIBLIOGRÁFICAS}

BIELSHO WSKY, R. Pensamento Económico Brasileiro. Brasflia: IPEA/INPES, 1988.

FURTADO, C. A Economia Latino-Americana. São Paulo: Nacional, 1986.
GERCHENKRON, A. Atraso Económico y industrialización. Barcelona: Ariel, 1970.

SALLUM JÚNIOR, B. Por Que Não Tem Dado Certo: notas sobre a transição polftica brasileira. IN: SOLA, L. OEstado da Transição: polftica e economia na Nova República. São Paulo: Vértice, 1988. 